\title{
Investigation of Rheological Behavior of Low Pressure Injection Molded Stainless Steel Feedstocks
}

\author{
Muhammad Aslam, ${ }^{1}$ Faiz Ahmad, ${ }^{1}$ Puteri Sri Melor Binti Megat Yusoff, ${ }^{1}$ Khurram Altaf, \\ Mohd Afian Omar, ${ }^{2}$ H. P. S. Abdul Khalil, ${ }^{3}$ and M. Rafi Raza ${ }^{4}$ \\ ${ }^{1}$ Department of Mechanical Engineering, Universiti Teknologi PETRONAS, Malaysia \\ ${ }^{2}$ Advanced Materials Research Centre (AMREC), SIRIM Berhad, Kulim, Malaysia \\ ${ }^{3}$ School of Industrial Technology, Universiti Sains Malaysia, Malaysia \\ ${ }^{4}$ Department of Mechanical Engineering, COMSATS Institute of Information Technology, Sahiwal, Pakistan
}

Correspondence should be addressed to Faiz Ahmad; faizahmad@petronas.com.my

Received 16 August 2015; Accepted 21 December 2015

Academic Editor: Charles C. Sorrell

Copyright (C) 2016 Muhammad Aslam et al. This is an open access article distributed under the Creative Commons Attribution License, which permits unrestricted use, distribution, and reproduction in any medium, provided the original work is properly cited.

\begin{abstract}
The purpose of this research is to investigate the influence of different powder loadings of 316L stainless steel (SS) powders on rheological behavior of feedstocks required for low pressure powder injection molding (L-PIM) process. The main idea consists in development of various formulations by varying 316L SS powder contents in feedstocks and evaluating the temperature sensitivity of feedstock via flow behavior index and activation energy. For this purpose, the irregular shape, spherical shape, and combination of both shapes and sizes (bimodal approach) of 316L SS powders are compounded with wax based composite binder. Moreover, the influence of elemental nanosized boron $(n \mathrm{~B})$ addition (up to $1.5 \mathrm{wt} . \%$ ) on rheological properties of irregular shape 316L SS powders is also evaluated using capillary rheometer method. It is observed that rheological parameters for solid powder loading of powder gas atomized (PGA) and bimodal powder P25/75 316L SS underwent sudden change from PGA-69 vol.\% to PGA-72 vol.\% and P25/75-67 vol.\% to P25/75 316L SS 70 vol.\%, respectively. Thus it is concluded that PGA-69 vol.\% and P25/75-67 vol.\% are optimal powder solid loadings corresponding to the lowest values of activation energies.
\end{abstract}

\section{Introduction}

Powder injection molding (PIM) is used as replacement for conventional powder metallurgy (PM) process to produce net shape components with high surface quality and close tolerance at low cost [1]. Binder is introduced in PIM and it is a temporary transport that helps powders packing into a desired shape until the commencement of sintering process. The mixture of powder and binder is named as feedstock. Binders play a vital role in the success of PIM process. Several binder systems are available and selection depends upon shape, size, and distribution of powders $[2,3]$. The binder suitability for PIM process depends on its characteristics of low viscosity, less molecular weight, and inexpensive modifier and it should be environmental friendly $[2,4]$. Usually, the thermoplastic binders are used for PIM process because these can be recycled easily and save the cost $[5,6]$.
Mixing of powder with binder is an important factor and it affects the flowability of feedstock during PIM process $[2,7]$. For low pressure molding, it is important to predict the flow behavior of feedstock; otherwise poor flowability and high viscosity lead toward many molding defects. Powder solid loading is another important factor and it influences the final properties of molded samples [8]. There is an optimal ratio between powder particles and binder that improves the quality and densification because of tight powder packing [9]. Solid loading and temperature affect the viscosity of various feedstocks. A high solid loading shows the minimum compact volume shrinkage and it is easy to control the dimensions of parts. Low shrinkage plays an important role in the mass production of intricate parts. On the other side, too high loading will enhance the viscosity of feedstock and it may cause failures in PIM [2]. 


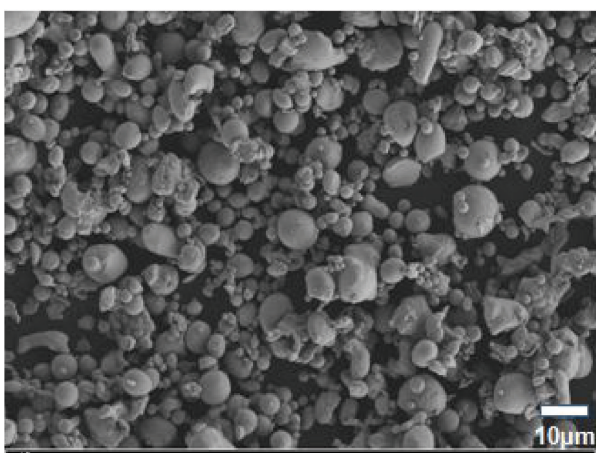

(a)

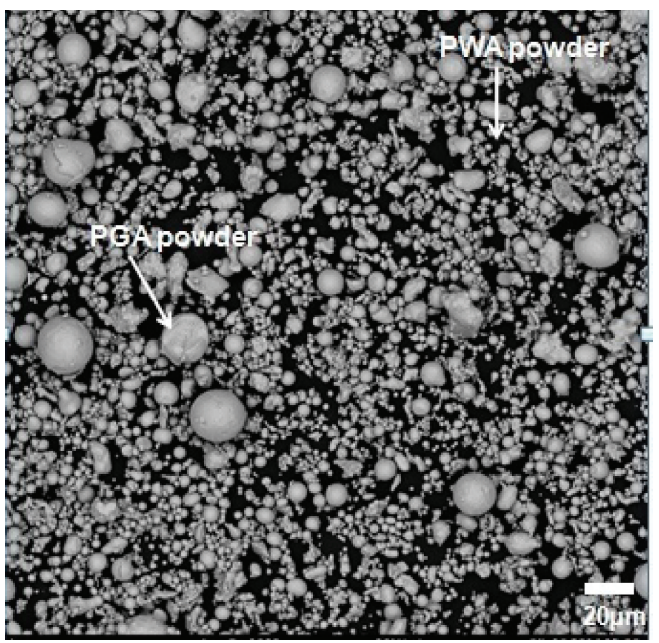

(c)

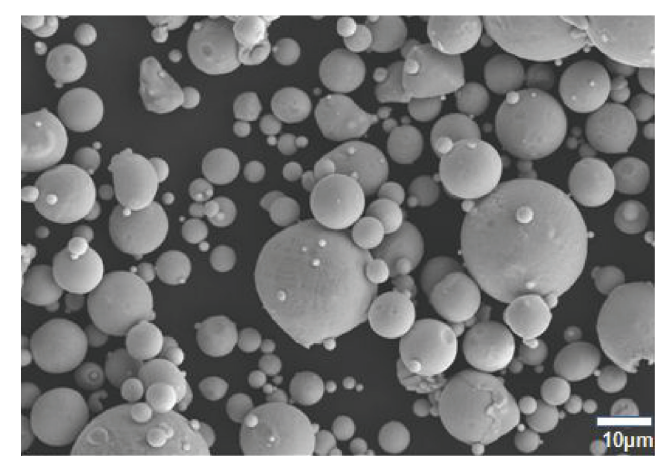

(b)

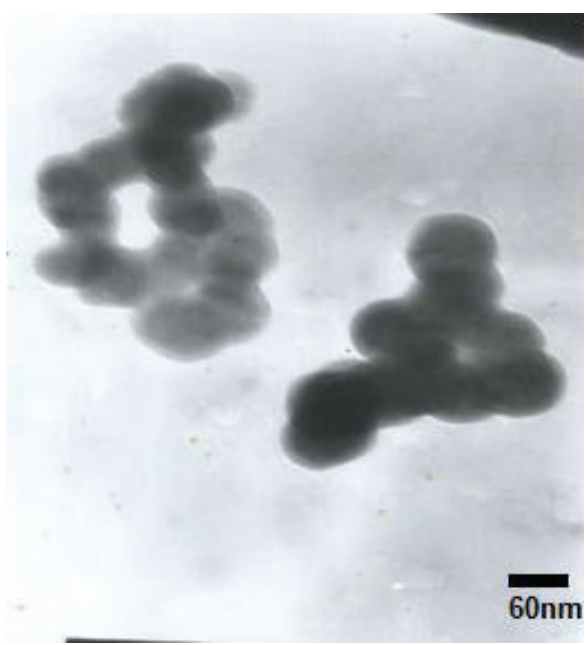

(d)

FIGURE 1: Raw materials for (a) PWA 316L SS and (b) PGA 316L SS and (c) P25/75 316L SS and (d) boron nanosized powder.

Most researchers [10-13] have focused on the powder packing density and very less attention has been paid to evaluate the rheological parameters for bimodal powder mixtures feedstocks and admixed $n \mathrm{~B}$ 316L SS feedstocks. Thus the present study investigates the rheological properties of various feedstocks and it involves the effect of quantitative measurement of solid loading and temperature on viscosity in terms of flow behavior index and activation energy for low pressure injection molding.

\section{Materials and Methods}

2.1. Raw Materials. The starting materials used in this research are powder gas atomized 316L stainless steel (PGA 316L SS), powder water atomized 316L stainless steel (PWA $316 \mathrm{~L} \mathrm{SS})$, and nanosized boron $(n \mathrm{~B})$ powders. Three main formulations are designed and developed comprising PGA, PWA- $n \mathrm{~B}$ powder mixture, and bimodal mixture of two powders PGA and PWA in the ratio of $25 \mathrm{vol} . \%$ and $75 \mathrm{vol} . \%$ (P25/75 316L SS) as shown in Figure 1. The bimodal powder mixtures play a vital role in shape retention and save the cost up to $10 \%$ as compared to monosized spherical powder [14]. $\mathrm{D}_{50}$ size of PWA, PGA, and $n \mathrm{~B}$ was measured using MASTER SIZER 2000 and these are $6.9 \mu \mathrm{m}, 20 \mu \mathrm{m}$, and
60-80 $\mathrm{nm}$, respectively. The composition of SS powder and binder ingredients to prepare various feedstocks was selected as shown in Table 1. The polypropylene (PP) component of binder is used as backbone, paraffin wax (PW) is used as flow promoter, and stearic acid (SA) is used as surfactant. Figure 2 shows DSC and TGA analysis for binder components used for making various formulations. It is evident from Figure 2(a) that melting temperature for $\mathrm{SA}, \mathrm{PW}$, and $\mathrm{PP}$ is $65^{\circ} \mathrm{C}, 55^{\circ} \mathrm{C}$, and $160^{\circ} \mathrm{C}$, respectively. Figure 2(b) shows that the binder starts to decompose at $200^{\circ} \mathrm{C}$ and ends at $450^{\circ} \mathrm{C} \sim 470^{\circ} \mathrm{C}$. Hence the solvent and thermal debinding cycles would be designed within these temperature limits.

2.2. Feedstock Preparation. For preparation of PWA- $n \mathrm{~B}$, P25/75, and PGA feedstocks, all powders are dried in oven at $85^{\circ} \mathrm{C}$ for $8 \mathrm{~h}$ to remove the moisture from powders. These powders were blended in the presence of stearic acid using turbular mixer. Stearic acid was coated on the surface of powders uniformly. PWA- $n \mathrm{~B}, \mathrm{PGA}$, and P25/75 powder mixtures were prepared using turbular mixer for $90 \mathrm{~min}$ at $40 \mathrm{rpm}$. In order to investigate the flowability, various formulations were prepared using z-blade mixer. In first step, the coated PWA- $n \mathrm{~B}, \mathrm{P} 25 / 75$, and PGA powder mixtures were mixed with paraffin wax for 10 minutes at $50^{\circ} \mathrm{C}$ in 


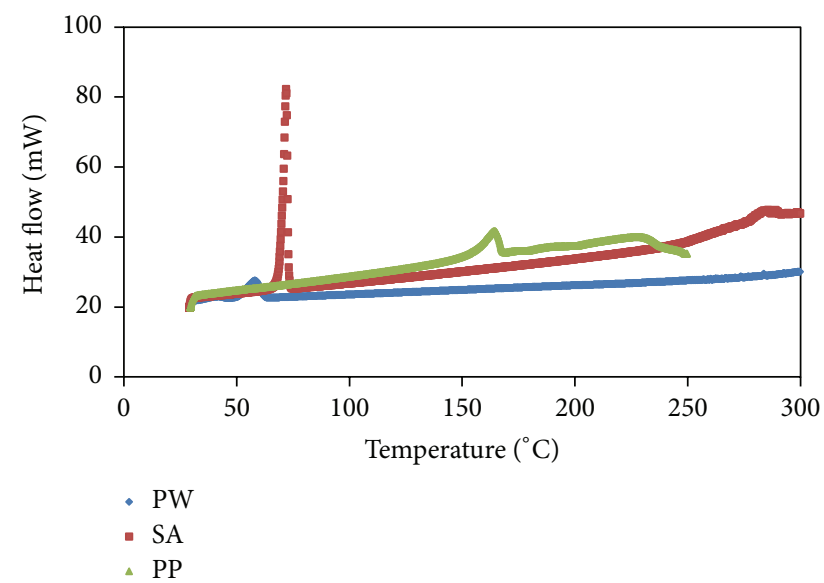

(a)

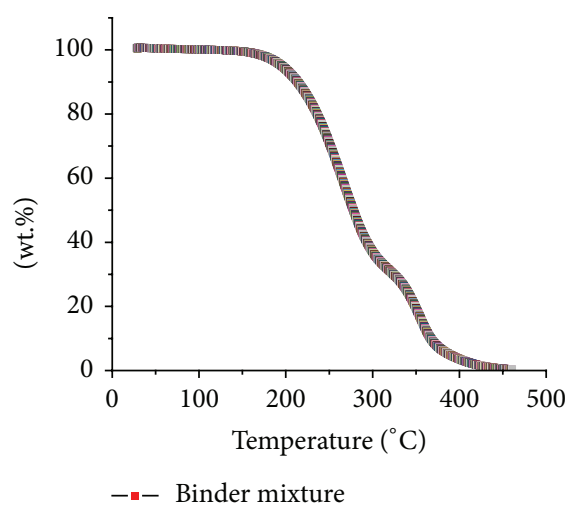

(b)

Figure 2: Binder components. (a) DSC analysis, (b) TGA analysis.

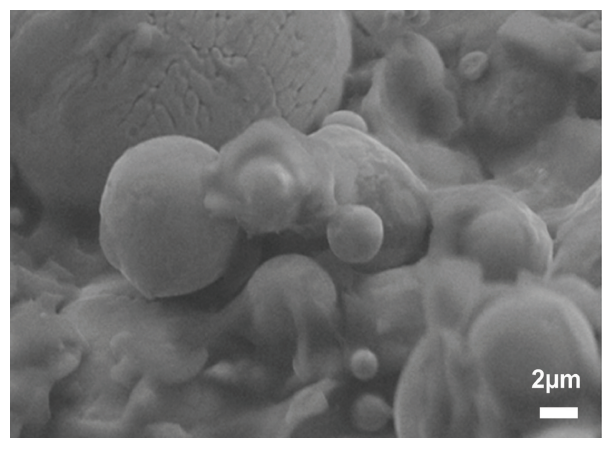

(a)

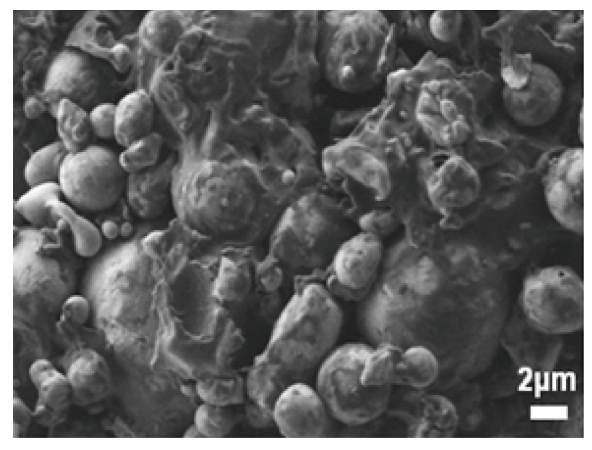

(b)

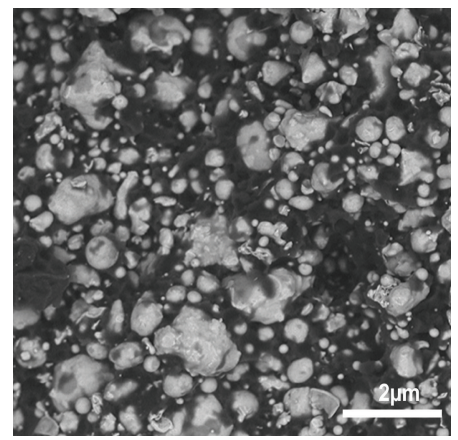

(c)

Figure 3: SEM micrographs of feedstocks for (a) PGA powders, (b) P25/75 mixture powders, and (c) PWA- $n$ B mixture powder.

z-blade mixer. Then temperature of $\mathrm{z}$-blade was raised to $170^{\circ} \mathrm{C} \pm 5^{\circ} \mathrm{C}$ and all powder mixtures were compounded for $90 \mathrm{~min}$ at $60 \mathrm{rpm}$. The details of PWA- $n \mathrm{~B}$, PGA, and P25/75 formulations were given in Table 1. In order to ensure the uniform dispersion of powders and binders in feedstock, mixtures were solidified and granulated using commercially available granulator. Three types of feedstocks consisting of PGA, P25/75, and PWA- $n$ B powder mixtures are shown in Figure 3. It is clear from Figure 3 that there is uniform dispersion of powder particles in the binder mixtures and all powders particles are coated with the thin layer of binder. The flow behavior of these formulations was determined using capillary rheometer CFT-500D.

2.3. Rheological Analysis for Feedstocks. The viscosity of all feedstocks was measured using CFT-500D capillary rheometer. A die with $1 \mathrm{~mm}$ diameter $(D)$ and $10 \mathrm{~mm}$ length $(L)$, giving a ratio of $(L / D) 10$, was used to measure the viscosity of feedstocks.

The test temperatures were $160^{\circ} \mathrm{C}, 170^{\circ} \mathrm{C}$, and $180^{\circ} \mathrm{C}$ that are beyond the melting temperature of backbone component of binder system. A preheating time was given 300 seconds to reach the thermal equilibrium after charging of rheometer barrel. Viscosity for all feedstock was measured by applying the different shear rates at three different temperatures as mentioned above. The viscosity upper limit for L-PIM process should be below $40 \mathrm{~Pa} \cdot \mathrm{S}$ as studied by Bose and German [2]. Here it is pertinent to mention that shear rate in the range of $10^{2}$ to $10^{5} \mathrm{~S}^{-1}$ falls in normal range of shear rate for L-PIM feedstocks [15].

The value of flow behavior index $(n)$ is deduced from the slope of graph drawn between the log value of shear rate and natural logarithm viscosity. Its value is calculated using the following equation [16]:

$$
\eta=K \gamma^{n-1},
$$

where $\eta$ is viscosity and $K$ is constant, $\gamma$ is shear rate, and $n$ is flow behavior index.

The activation energy $E$ for all feedstocks is calculated taking the slope of graphs between log-log scale of reciprocal of temperature and viscosity at constant shear rate $4000 \mathrm{~S}^{-1}$. $E / R$ that is slope of the graph can be calculated using Arrhenius equation [17]:

$$
\eta=\eta_{o} \exp \left(\frac{E}{R T}\right)
$$


TABLE 1: Components used for preparation of various feedstocks.

\begin{tabular}{lccc}
\hline Formulations & Powder (vol.\%) & Binder & PW (vol.\%) \\
& & PP (vol.\%) & 24.05 \\
SA (vol.\%)
\end{tabular}

where $\eta$ is viscosity, $\eta_{o}$ is reference viscosity, and $R$ is gas constant and its value is $8.3144 \mathrm{~J} / \mathrm{K} \cdot \mathrm{mol}$.

\section{Results and Discussion}

3.1. Viscosity Measurement. Figures 4, 6, and 8 show results related to rheological measurement of PGA powders, PWA$n \mathrm{~B}$ powder mixtures, and $\mathrm{P} 25 / 75$ powder mixtures feedstocks, respectively, at three different temperatures $160^{\circ} \mathrm{C}, 170^{\circ} \mathrm{C}$, and $180^{\circ} \mathrm{C}$. It is further observed that, for low pressure molding, the viscosity upper limit is below $40 \mathrm{~Pa} \cdot \mathrm{S}$ and it is in agreement with studies realized by Bose and German for low pressure molding [2]. It is also observed that viscosity for all powder mixtures feedstocks depends on temperature, solid loading, and shear rate. Rheological behavior for three types of formulations' set is described in detail.

3.1.1. Rheological Analysis for PGA Feedstocks. Figure 4 shows the relationship between shear rate and viscosity at $160^{\circ} \mathrm{C}$, $170^{\circ} \mathrm{C}$, and $180^{\circ} \mathrm{C}$ for various powder mixture feedstocks on $\log -\log$ scale. From Figure 4 it is observed that the viscosity decreases with an increase of shear rate. This shear thinning behavior is considered due to orientation and ordering of binder molecules in flow directions [2]. This phenomenon is desired in PIM because it restrains the risk of powder binder separation. Moreover, from these figures, viscosity trend is observed toward low plateau and it is disproportionate increase in particle-particle contacts that hinders flow at high shear rate. Here it is pertinent to mention that shear rate in the range of $10^{2}$ to $10^{5} \mathrm{~S}^{-1}$ falls in normal range of shear rate for PIM feedstocks [15].

Table 2 shows the value of flow behavior index $(n)$ that is deduced from the slope of graph drawn between the log shear rate and natural logarithm viscosity. It can be seen in Table 2 that as the solid loading is increased from 63 vol. \% to 72 vol. \%, the value of $n$ decreases and it is due to influence of shear rate on the breakage of agglomeration in PGA feedstock. This result is in agreement with the studies conducted by researchers [18]. Moreover, the value of $n$ describes the
TABLE 2: Values of $n$ and $E$ for PGA feedstocks.

\begin{tabular}{lccc}
\hline Formulations & $\begin{array}{c}\text { Temperature } \\
\left({ }^{\circ} \mathrm{C}\right)\end{array}$ & $\begin{array}{c}\text { Flow } \\
\text { behavior } \\
\text { index } \\
(n)\end{array}$ & $\begin{array}{c}\text { Activation energy } \\
(E) \\
(\mathrm{KJ} / \mathrm{mol})\end{array}$ \\
\hline \multirow{2}{*}{ PGA-63 } & 160 & 0.75 & \\
& 170 & 0.65 & 36.9 \\
\hline \multirow{3}{*}{ PGA-66 } & 180 & 0.49 & \\
& 160 & 0.65 & 33.3 \\
PGA-69 & 170 & 0.63 & 31.3 \\
& 180 & 0.42 & \\
\hline \multirow{3}{*}{ PGA-72 } & 160 & 0.63 & \\
& 170 & 0.60 & 38.2 \\
\hline
\end{tabular}

feedstock behavior and its suitability for injection molding process. Thus lower value of $n$ is desirable to produce the complex geometry parts because of high degree of shear sensitivity of feedstock. In turn, higher value of $n$ exhibits the better rheological stability of feedstock and provides a good retention of shape of parts. In this research work, it is evident from Table 2 that at lower temperature, that is, $160^{\circ} \mathrm{C}$, the value of $n$ is higher and it becomes lower at high temperature, that is, $180^{\circ} \mathrm{C}$. Thus, in order to get the advantage of both rheological stability and high shear sensitivity of feedstock, the molding temperature is selected in between, that is, $170^{\circ} \mathrm{C}$. However, the obtained results for the flow behavior index are in the range of 0.32 to 0.75 and this value is less than 1. A low value of $n$ demonstrates that the viscosity is more dependent on shear rate. However, a very low $n$ value initiates the defects in molded parts due to slip flow phenomena in the mixture [19]. Thus, $n$ value shows that all PGA feedstock have high pseudoplastic properties and facilitate the process 


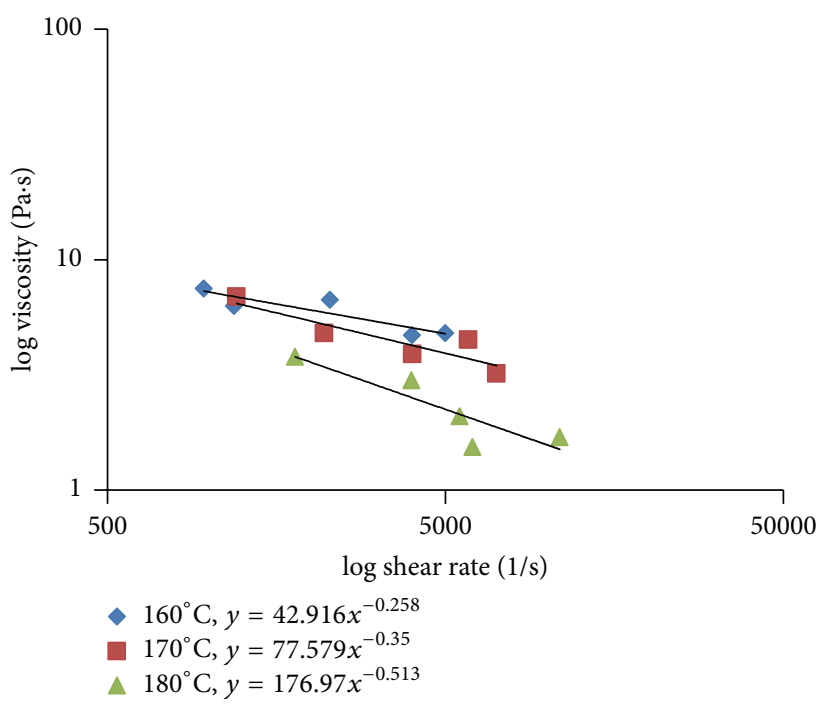

(a)

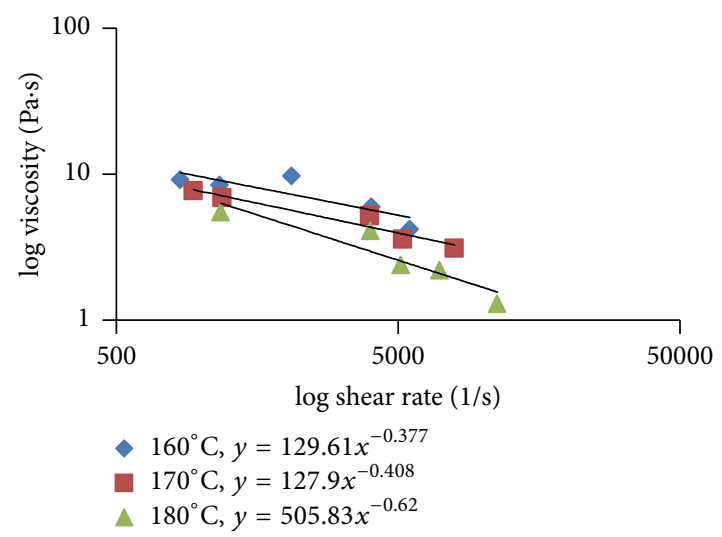

(c)

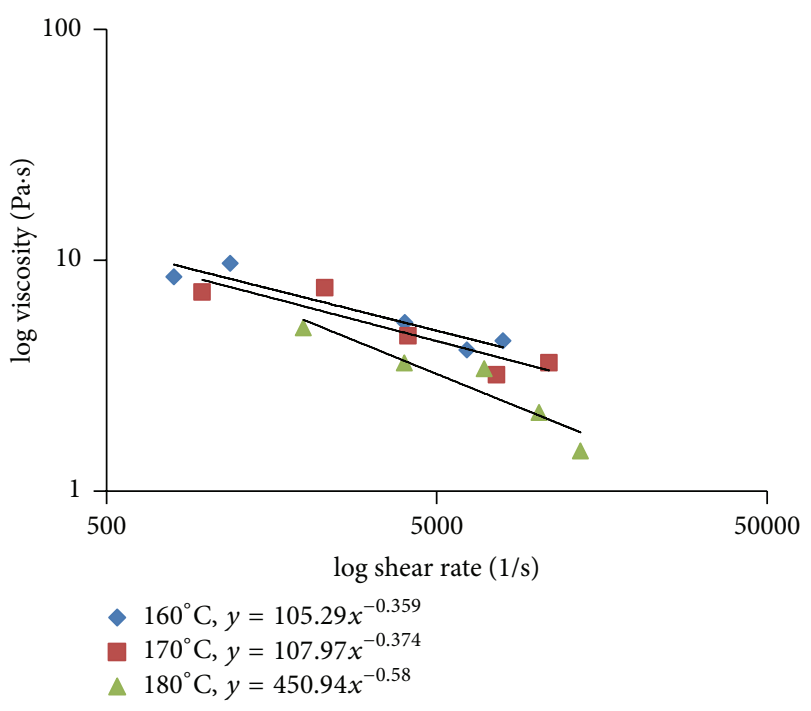

(b)

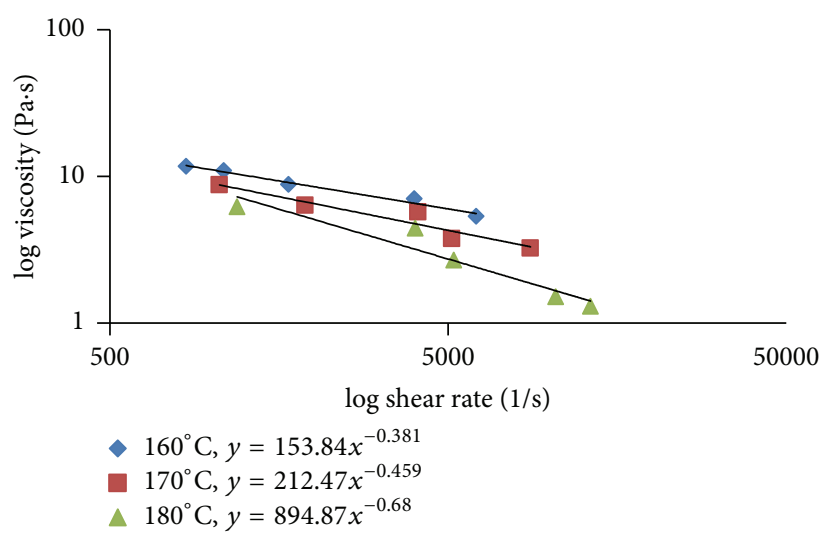

(d)

FIgure 4: Viscosity results for (a) PGA-63, (b) PGA-66, (c) PGA-69, and (d) PGA-72 feedstocks.

of injection molding. These results are in agreement with the studies conducted by Li and Muhamad [20].

Figure 5 also shows the viscosity dependence of various feedstocks on temperature and it determines the value of activation energy $E$. It is clear from Figure 5 that 72 vol. $\%$ of powder loading has broad range of viscosities as compared to 63 vol.\% loading. It means that 63 vol. $\%$ is highly sensitive to temperature change as compared to 72 vol. $\%$ loading. So it reflects that any sudden change in temperature during molding of 63 vol. $\%$ will cause stress concentration in molded parts that may lead toward cracks as compared to 72 vol.\%. Equation (2) can establish the relationship between temperature and viscosity at constant shear rate $4000 \mathrm{~S}^{-1}$. E must be low to facilitate feedstock flow into mold. $E / R$ is slope of the graph and it can be calculated by taking the slope of the lines as shown in Figure 5 using Arrhenius equation [17]. Table 2 shows that the activation energy $E$ of PGA-63 is higher than PGA-66 and it decreases by enhancing the solid loading in feedstocks until 69 vol.\%. It is safely derived that as solid loading is increased the volume expansion of binder becomes low and it ultimately enhances the viscosity due to close particle-particle interaction. In this study, the activation energy $E$ is derived by plotting $\ln n$ and $1 / T$ at a constant shear rate $4000 \mathrm{~S}^{-1}$ as shown in Figure 5. The value of $E$ varies by changing the powder content. As the powder content increases the activation energy decreases and it again starts to increase as it exceeds the $69 \mathrm{vol} . \%$ powder loading. The increase in powder loading basically enhances the viscosity and more energy is required to mobilize the molecules from one site to other sites. The change in viscosity is an inherent property of the binder and addition of powder particles minimizes the thermal sensitivity of organic binder. It is seen that the activation energy value for $69 \mathrm{vol} . \%$ is $31.312 \mathrm{KJ} / \mathrm{mol}$ and it corresponds to the lowest sensitivity of viscosity to temperature as compared to PGA- $63 \mathrm{vol} . \%$, that is, $36.93 \mathrm{KJ} / \mathrm{mol}$. Thus PGA-69vol.\% is more appropriate to be injection molded in a wide temperature range. Thus PGA- 69 vol. $\%$ is the optimal solid loading. It is believed that PGA-69 vol.\% feedstock has appropriate powder-to-binder ratio and it assists in maintaining the stable flow behavior of feedstock. 


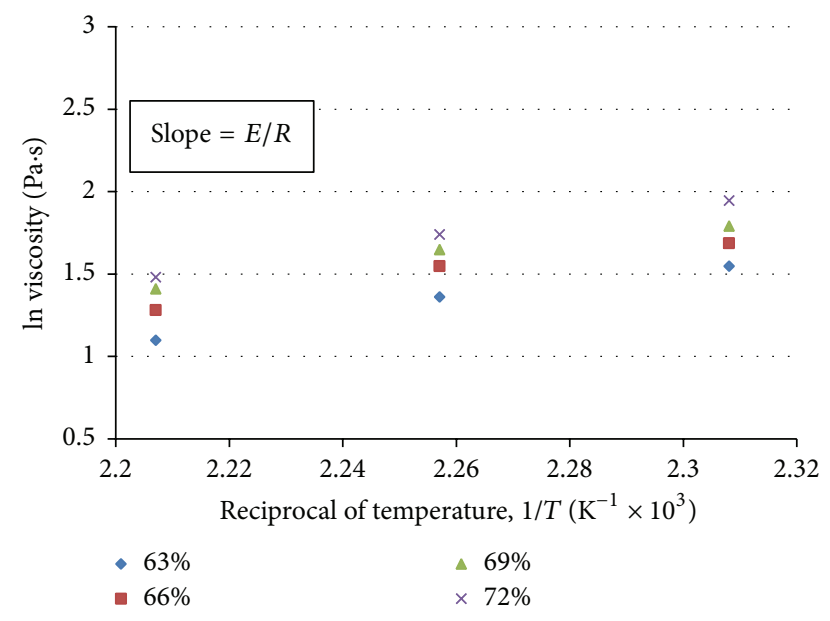

FIGURE 5: A relationship between viscosity and temperature for various PGA formulations.

TABLe 3: Values of $n$ and $E$ for PWA-B feedstocks.

\begin{tabular}{lccc}
\hline Formulation & Temp $\left({ }^{\circ} \mathrm{C}\right)$ & $\begin{array}{c}\text { Flow behavior } \\
\text { index }(n)\end{array}$ & $\begin{array}{c}\text { Activation energy, } \\
E(\mathrm{KJ} / \mathrm{mol})\end{array}$ \\
\hline \multirow{4}{*}{ PWA-0B } & 160 & 0.70 & \\
& 170 & 0.61 & 21.3 \\
\hline \multirow{4}{*}{ PWA-0.5B } & 180 & 0.59 & \\
& 160 & 0.59 & 19.4 \\
\hline \multirow{4}{*}{ PWA-1B } & 170 & 0.54 & \\
& 180 & 0.49 & 17.1 \\
\hline \multirow{4}{*}{ PWA-1.5B } & 160 & 0.51 & \\
& 170 & 0.46 & 22.7 \\
\hline
\end{tabular}

3.1.2. Rheological Analysis for PWA-nB Feedstocks. Nanosized elemental boron is added in PWA stainless steel with loading from 0.5 to $1.5 \mathrm{wt} \%$. Due to nanosize, its surface area is larger in preparation of feedstocks. It is evident from Figure 6 that viscosity of feedstock containing $1.5 \mathrm{wt}$.\% boron is higher compared to $0 \mathrm{wt} . \% \mathrm{~B}, 0.5 \mathrm{wt} . \% \mathrm{~B}$, and $1 \mathrm{wt} . \%$ B. As boron powder concentration is increased in powder mixture, large surface area of $n \mathrm{~B}$ powder and its good interstitial packing within the stainless steel powder particles enhance the viscosity of feedstocks. Moreover, surfactant that is used for wetting purposes plays an important role in bridging between the binder and powder particles through a functional group. This functional group establishes a strong contact with $n \mathrm{~B}$ particles due to their large surface area and extends its molecular chain into binder. Thus large surface area of $n \mathrm{~B}$ powder admixed with PWA 316L SS results in low binder expansion and low disentanglement of molecular chain which ultimately increase the viscosity of feedstock.
TABLE 4: Values of $n$ and $E$ for P25/75 feedstocks.

\begin{tabular}{lccc}
\hline Formulations & Temp $\left({ }^{\circ} \mathrm{C}\right)$ & $\begin{array}{c}\text { Flow behavior } \\
\text { index }(n)\end{array}$ & $\begin{array}{c}\text { Activation energy, } \\
E(\mathrm{KJ} / \mathrm{mol})\end{array}$ \\
\hline \multirow{3}{*}{ P25/75-61 } & 160 & 0.63 & \\
& 170 & 0.59 & 48.4 \\
& 180 & 0.55 & \\
P25/75-64 & 160 & 0.58 & 41.9 \\
& 170 & 0.51 & \\
\hline \multirow{3}{*}{ P25/75-67 } & 180 & 0.47 & 37.9 \\
& 160 & 0.50 & \\
\hline \multirow{3}{*}{ P25/75-70 } & 170 & 0.48 & 42.0 \\
& 180 & 0.42 & \\
\hline
\end{tabular}

The value of flow behavior index falls in the range of 0.32 to 0.70 and it is less than 1 as shown in Table 3. Hence, all feedstocks exhibit the shear thinning behavior and powder mixtures are acceptable for PIM process. Moreover, activation energy for each formulation was calculated from slope of Figure 7 and it is observed that activation energy decreases due to addition of $n \mathrm{~B}$ particles in 316L SS powder mixture and it is due to enhancement of surface area of filler particles and reduction of binder expansion in boron added formulations. Due to large surface area and good thermal conduction of boron powder, they result in the high viscosity and low activation energy in powder mixtures. However, value of $E$ decreases up to $1 \mathrm{wt} . \%$ of boron and it rises again with the addition of boron up to $1.5 \mathrm{wt} . \%$. Thus optimal boron filler loading in 316L SS feedstock is to be considered $1 \mathrm{wt} . \%$ of boron. Moreover, it is derived from Figure 7 that PWA-0B is more temperature sensitive as compared to PWA-1.5B and hence its molding can produce the defects with little variation in temperature.

3.1.3. Rheological Analysis for P25/75 Feedstocks. In bimodal powder mixture, PGA, and PWA two types of powder are mixed with binder. PGA powder is spherical and large in size as compared to irregular PWA powder. Large particles of PGA fill the vacancies created by clustering of small PWA particles and help in releasing the binder to lubricate the surface of powder particles. This action improves the flowability of feedstock and lowers the viscosity. However, higher solid loading of P25/75 feedstocks will decrease the volume expansion of binder and enhances the viscosity. Larger particle-to-particle contact hinders the flowability but increases the temperature dependence of feedstock. A small fluctuation of molding temperature affects the flowability and induces the stresses that lead toward the failure of green samples. Figure 8 describes that viscosity of the bimodal mixture decreases with increase of shear rate and it touches the lower plateau at high shear rate. This shear thinning behavior is required for PIM process. The flow behavior index for various loading of P25/75 is summarized in Table 4. 


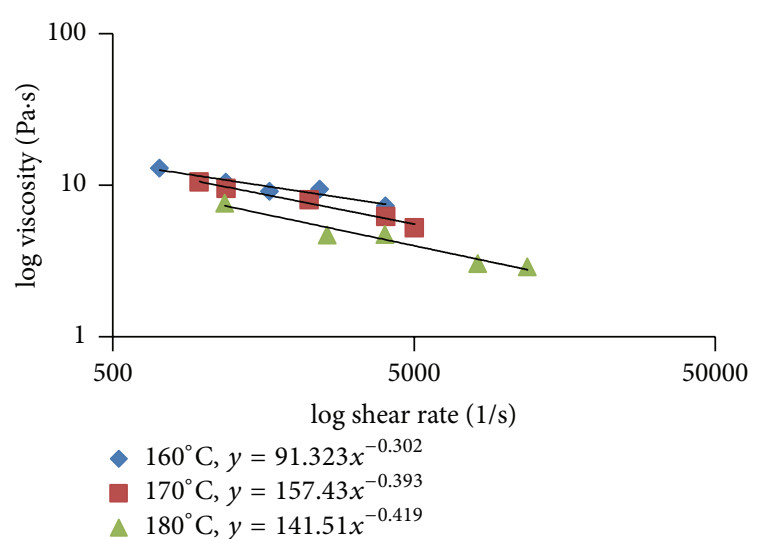

(a)

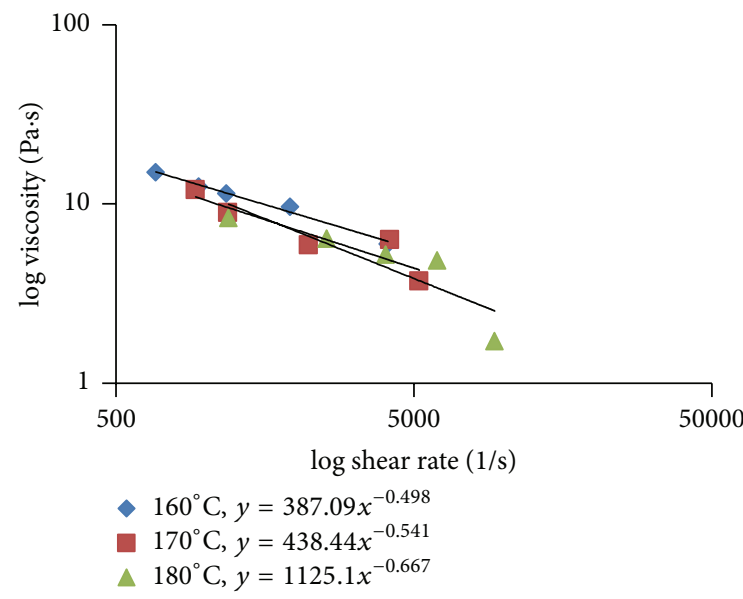

(c)

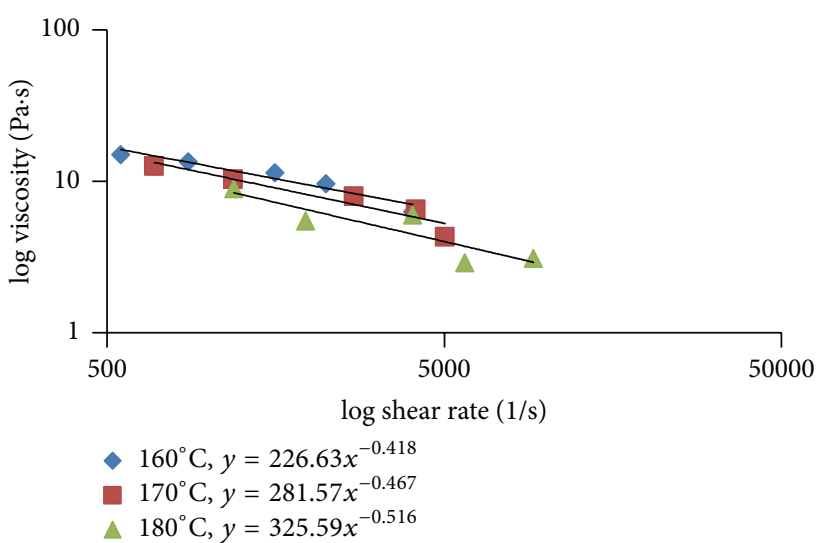

(b)

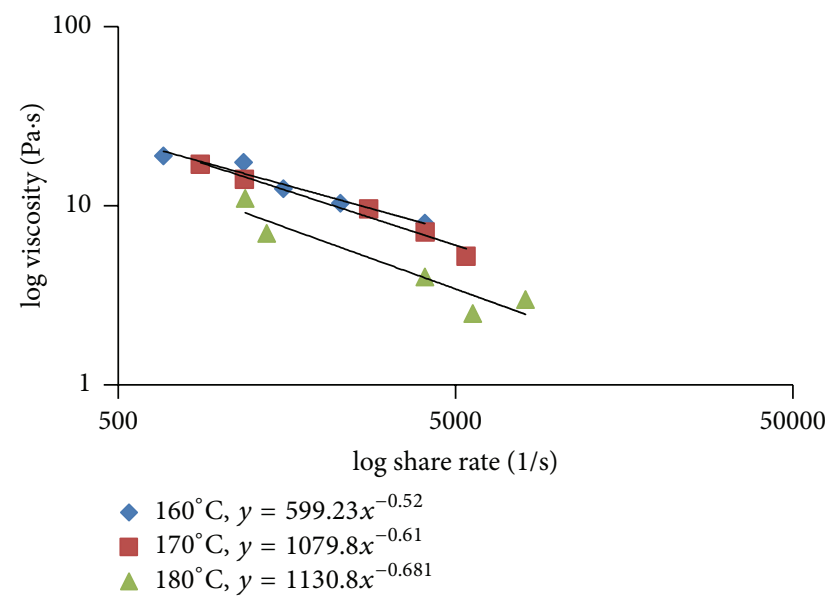

(d)

Figure 6: Viscosity results for (a) PWA-0B, (b) PWA-0.5B, (c) PWA-1B, and (d) PWA-1.5B feedstocks.

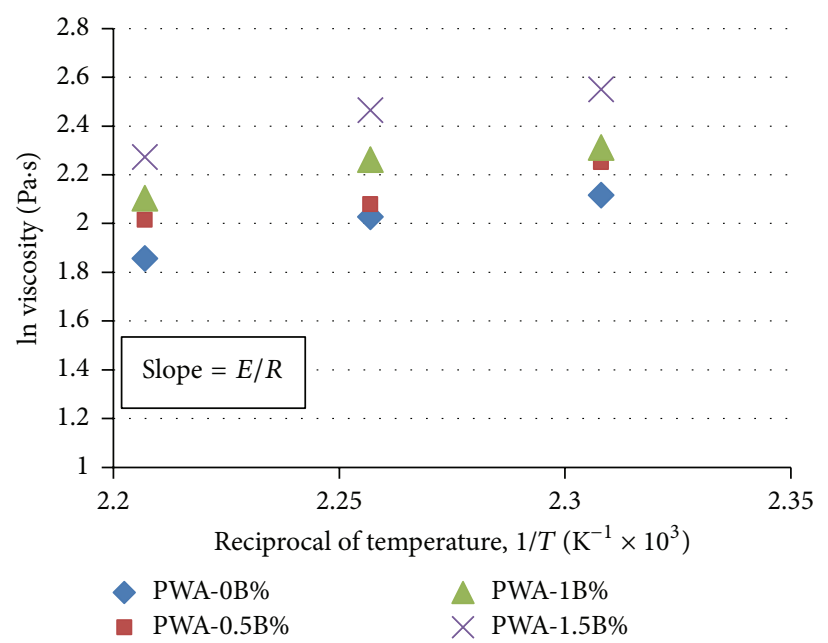

FIGURE 7: A relationship between viscosity and temperature for various PWA- $n$ B formulations. 


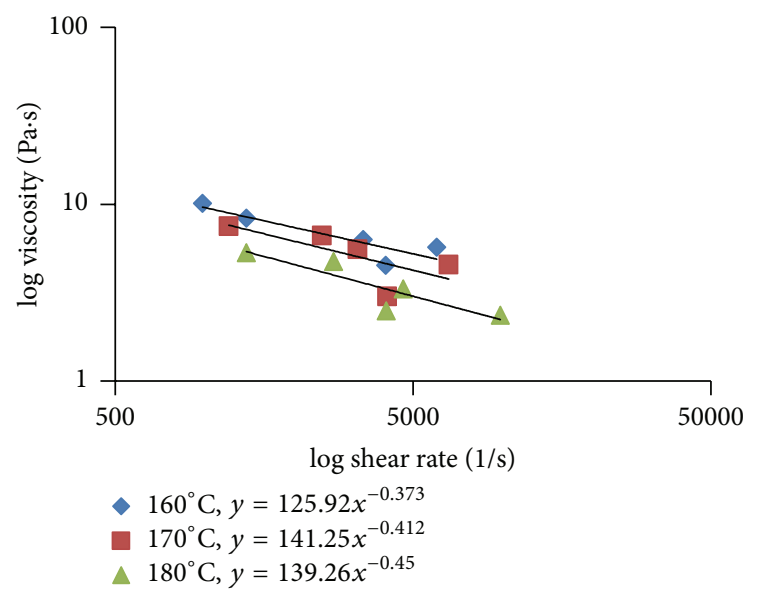

(a)

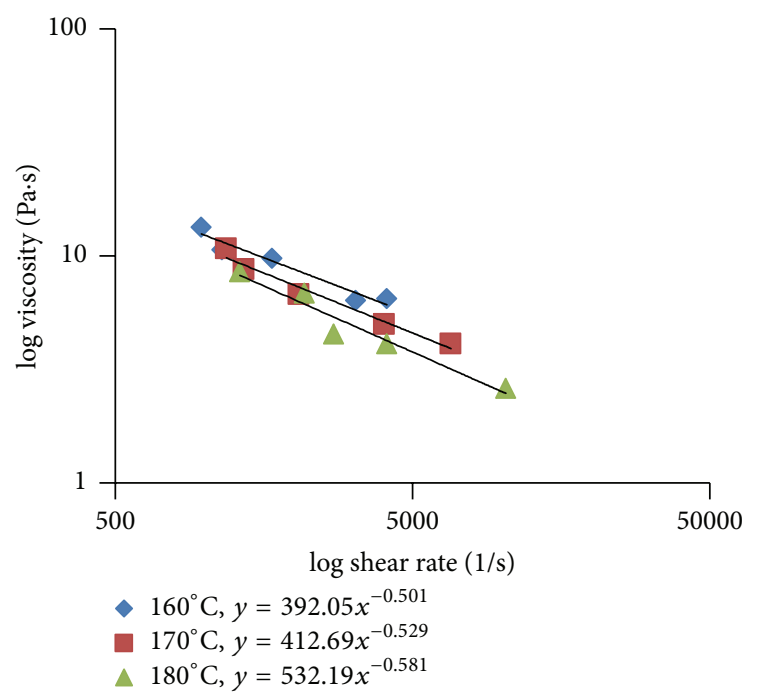

(c)

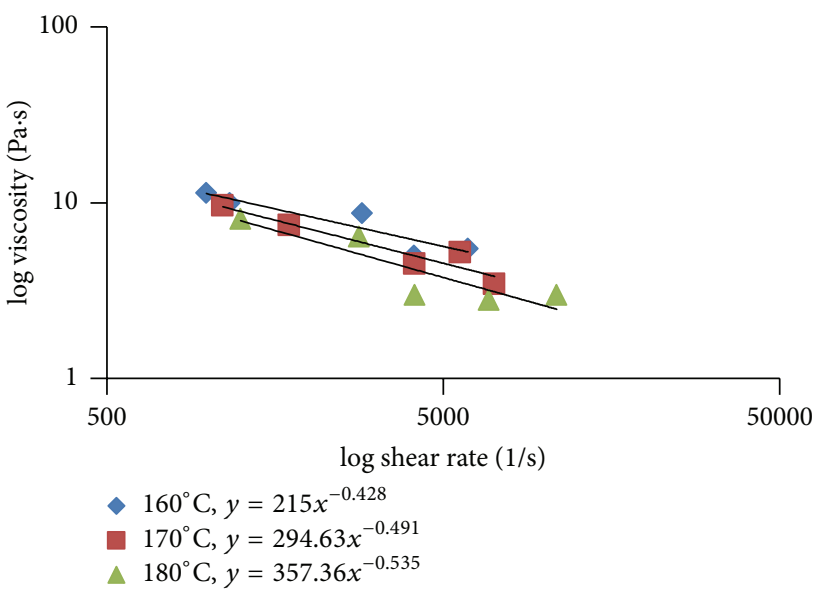

(b)

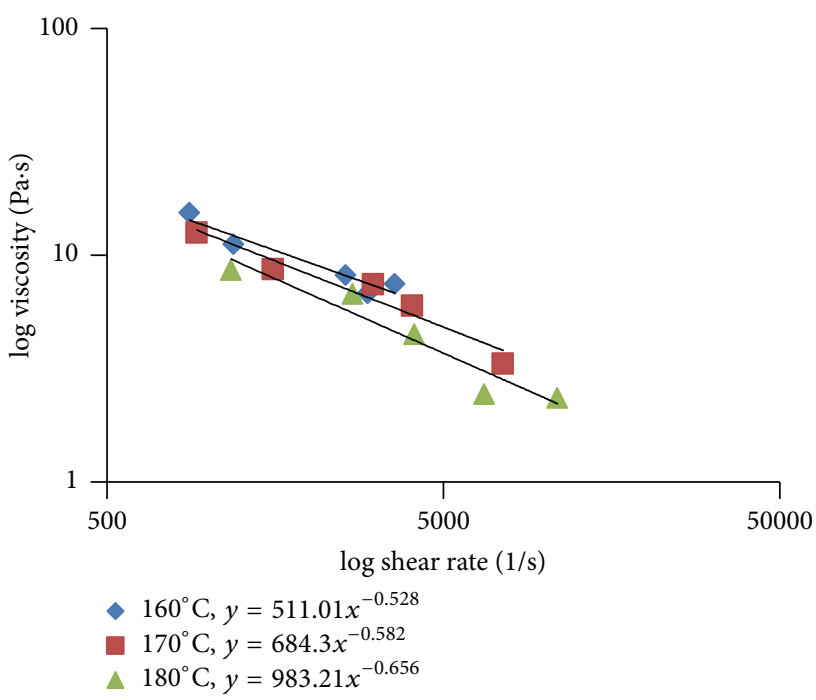

(d)

FIgUre 8: Viscosity results for (a) P25/75-61, (b) P25/75-64, (c) P25/75-67, and (d) P25/75-70 feedstocks.

It is clear that value of flow behavior index varies from 0.35 to 0.63 and this range decreases with increase of solid loading. This behavior shows that the value of $n$ is lower for P25/75-70 and it is critical powder-to-binder ratio for powder injection molding. However, the activation energy for these formulations decreases with the increase of solid loading up to 67 vol.\% and then increases again. So P25/7567 is to be considered the optimal powder-to-binder ratio for low pressure molding. The thermal behavior of P25/7567 is more stable as compared to P25/75-61 because of large viscosities range as shown in Figure 9.

\section{Conclusions}

The viscosity of feedstocks plays a vital role in determining the molding properties during low pressure injection molding. In this research work, a relationship between temperature and viscosity is established. An impact of low viscous (wax based) binder system on flow behavior index as well as thermal properties for various feedstocks is studied. Following conclusions are reached:

(1) For low pressure injection molding, the viscosities of all PGA, PWA- $n$ B, and P25/75 feedstock lie below $36 \mathrm{~Pa} \cdot \mathrm{S}$ and these feedstocks are appropriate for low pressure injection molding.

(2) The slope of viscosity and temperature relationship shows that activation energy for PWA-1B, PGA-69, and P25/75-67 feedstocks is $17.119 \mathrm{KJ} / \mathrm{mol}$, $31.312 \mathrm{KJ} / \mathrm{mol}$, and $37.946 \mathrm{KJ} / \mathrm{mol}$, respectively, and these values are the lowest with respect to other activation energies values for other respective formulations. Hence, PWA-1B, PGA-69, and P25/75-67 formulations are optimal solid loading.

(3) Flow behavior index values for all formulations are less than one at $160^{\circ} \mathrm{C}, 170^{\circ} \mathrm{C}$, and $180^{\circ} \mathrm{C}$ temperature and it shows that feedstock have shown the shear thinning behavior and these formulations are appropriate for low pressure injection molding. 


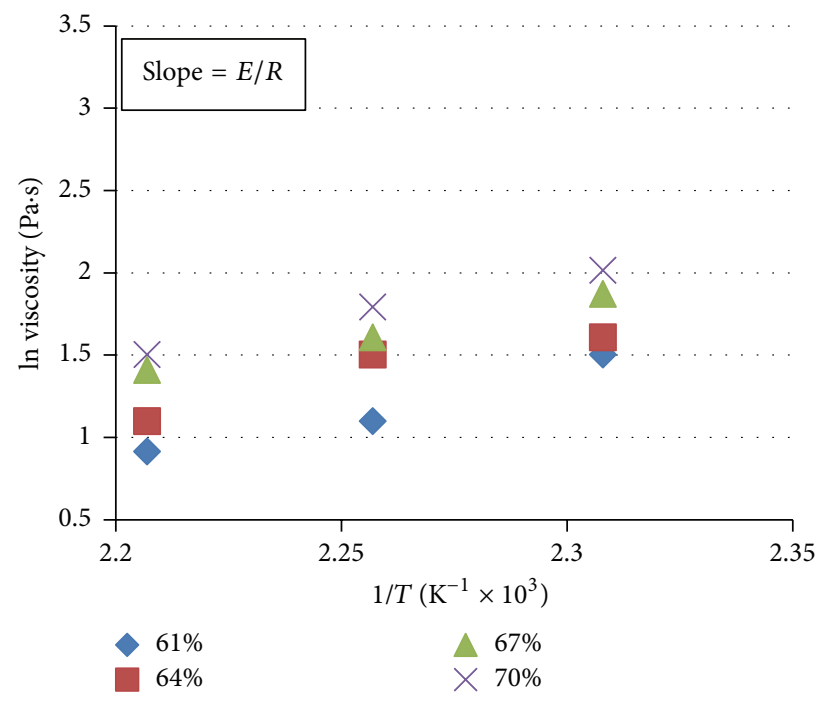

FIGURE 9: A relationship between viscosity and temperature for various $\mathrm{P} 25 / 75$ formulations.

(4) On the basis of flow behavior index and activation energy, it is concluded that all these feedstocks can be injection molded at $170^{\circ} \mathrm{C}$ using low pressure.

\section{Conflict of Interests}

The authors declare that there is no conflict of interests regarding the publication of this paper.

\section{Acknowledgment}

The authors would like to acknowledge the financial support provided by the Universiti Teknologi PETRONAS, Malaysia, for providing the resources under Graduate Assistant Scholarship Scheme to conduct this research in the conducive environment.

\section{References}

[1] C. Karatas and S. Saritas, "Rheological properties of mixed gas and water atomized stainless steel powder MIM feedstock," International Journal of Powder Metallurgy, vol. 37, no. 8, pp. 3944, 2001.

[2] A. Bose and R. M. German, Injection Molding of Metals and Ceramics, Metal Powder Industries Federation, Princeton, NJ, USA, 1997.

[3] X.-Q. Liu, Y.-M. Li, J.-L. Yue, and F.-H. Luo, "Deformation behavior and strength evolution of MIM compacts during thermal debinding," Transactions of Nonferrous Metals Society of China, vol. 18, no. 2, pp. 278-284, 2008.

[4] R. M. German, "Powders, binders and feedstocks for powder injection moulding," PIM International, vol. 1, no. 1, pp. 34-39, 2007.

[5] G. Bandyopadhyay and K. W. French, "Injection-molded ceramics: critical aspects of the binder removal process and component fabrication," Journal of the European Ceramic Society, vol. 11, no. 1, pp. 23-34, 1993.
[6] M. Imbaby, K. Jiang, and I. Chang, "Fabrication of 316L stainless steel micro parts by softlithography and powder metallurgy," Materials Letters, vol. 62, no. 26, pp. 4213-4216, 2008.

[7] B. C. Mutsuddy and R. G. Ford, Ceramic Injection Molding, Chapman \& Hall, London, UK, 1995.

[8] R. German, Powder Injection Molding, MPIF, Princeton, NJ, USA, 1990.

[9] S. J. Milne, M. Patel, and E. Dickinson, "Experimental studies of particle packing and sintering behaviour of monosize and bimodal spherical silica powders," Journal of the European Ceramic Society, vol. 11, no. 1, pp. 1-7, 1993.

[10] G. L. Messing and G. Y. Onoda Jr., "Inhomogeneity-packing density relations in binary powders-experimental studies," Journal of the American Ceramic Society, vol. 61, no. 7-8, pp. 363366, 1978.

[11] R. M. German, "Sintering densification for powder mixtures of varying distribution widths," Acta Metallurgica et Materialia, vol. 40, no. 9, pp. 2085-2089, 1992.

[12] M. R. Raza, F. Ahmad, M. A. Omar, and R. M. German, "Effects of cooling rate on mechanical properties and corrosion resistance of vacuum sintered powder injection molded 316L stainless steel," Journal of Materials Processing Technology, vol. 212, no. 1, pp. 164-170, 2012.

[13] M. Aslam, F. Ahmad, P. S. M. B. Yusoff, N. Muhamad, M. R. Raza, and M. I. Shirazi, "Effects of admixed titanium on densification of 316L stainless steel powder during sintering," MATEC Web of Conferences, vol. 13, 5 pages, 2014.

[14] B. N. Mukund, B. Hausnerova, and T. S. Shivashankar, "Development of 17-4PH stainless steel bimodal powder injection molding feedstock with the help of interparticle spacing/lubricating liquid concept," Powder Technology, vol. 283, pp. 24-31, 2015.

[15] B. Huang, S. Liang, and X. Qu, "The rheology of metal injection molding," Journal of Materials Processing Technology, vol. 137, no. 1-3, pp. 132-137, 2003.

[16] H. A. Barnes, J. F. Hutton, and K. Walters, An Introduction to Rheology, Elsevier, Philadelphia, Pa, USA, 1989.

[17] O. Novac, "The rheological behaviour of some binders and plastisols used in injection moulding," in Proceedings of the Powder Metallurgy World Congress(PM '94), pp. 1113-1116, Paris, France, June 1994.

[18] M. Khakbiz, A. Simchi, and R. Bagheri, "Investigation of rheological behaviour of 316L stainless steel-3 wt-\% TiC powder injection moulding feedstock," Powder Metallurgy, vol. 48, no. 2, pp. 144-150, 2005.

[19] S. Y. M. Amin, N. Muhamad, K. R. Jamaludin, A. Fayyaz, and H. S. Yunn, "Characterization of the feedstock properties of metal injection-molded WC-Co with palm stearin binder system," Sains Malaysiana, vol. 43, no. 1, pp. 123-128, 2014.

[20] H. P. Li and N. Muhamad, "Rheological analysis of microminiature powder injection molding ( $\mu \mathrm{PIM})$ feedstock," Applied Mechanics and Materials, vol. 52-54, pp. 238-243, 2011. 

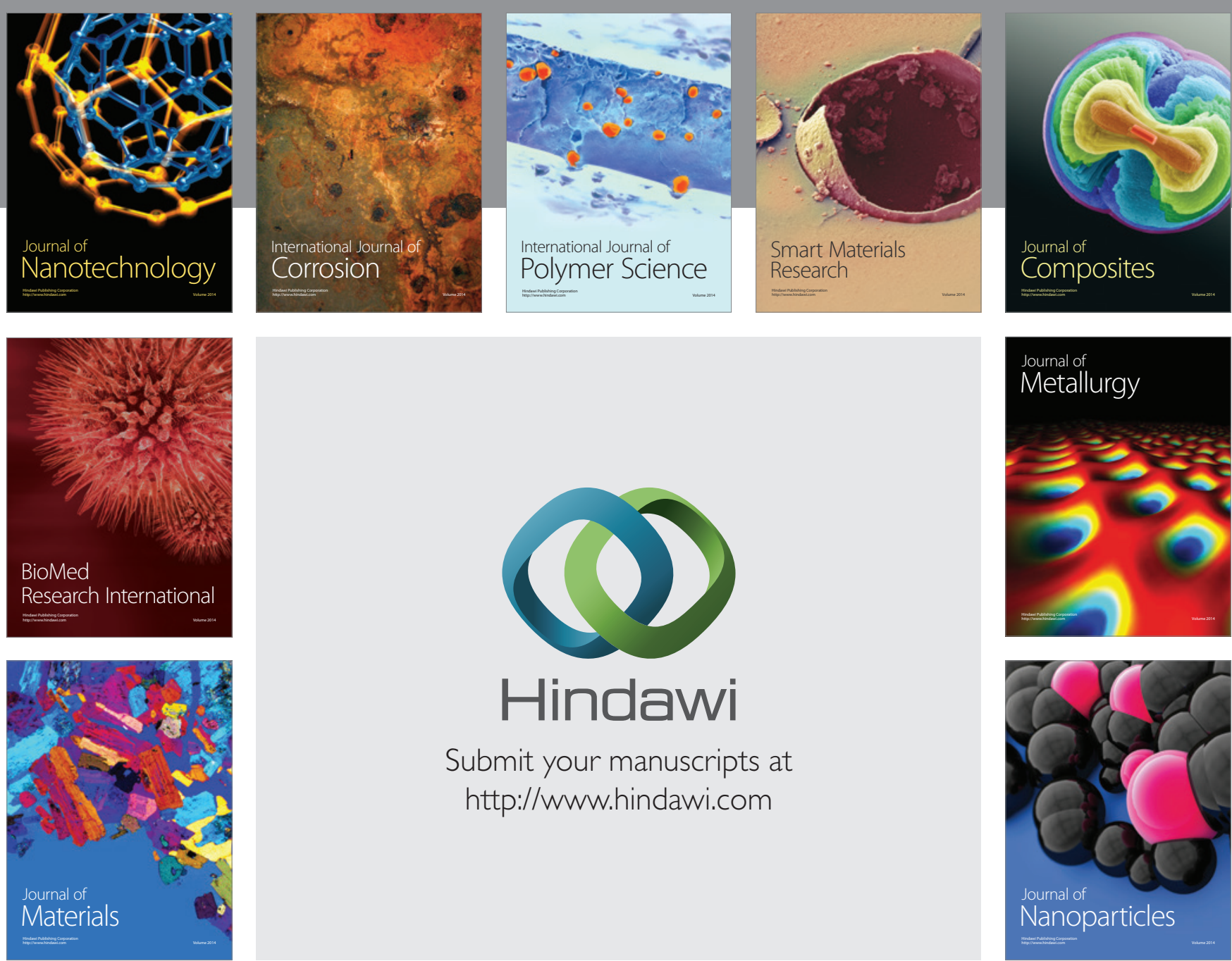

\section{Hindawi}

Submit your manuscripts at

http://www.hindawi.com

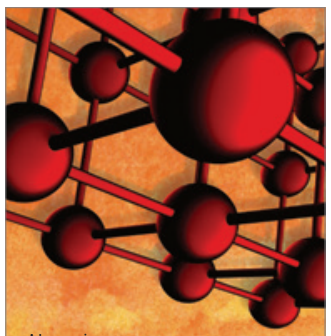

Materials Science and Engineering
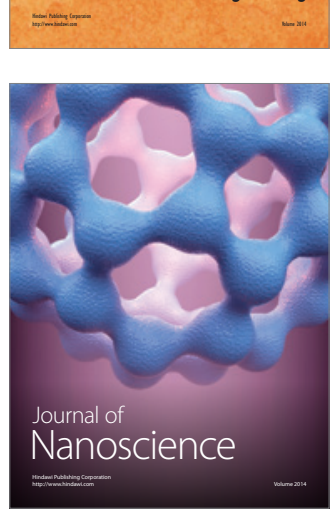
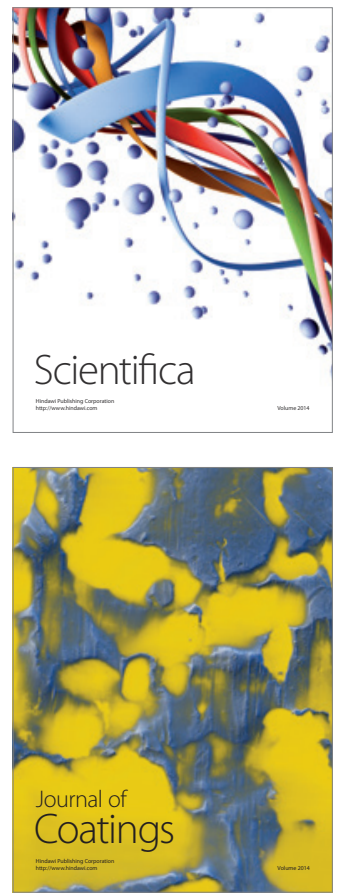
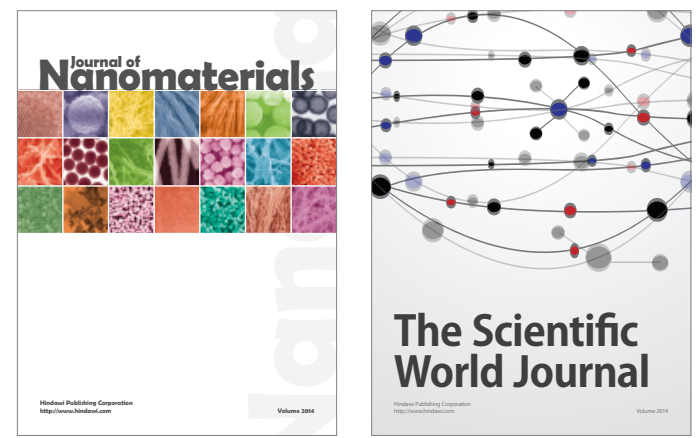

The Scientific World Journal
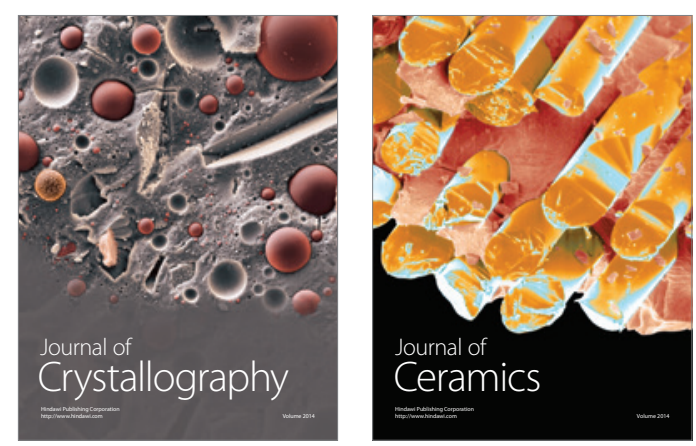
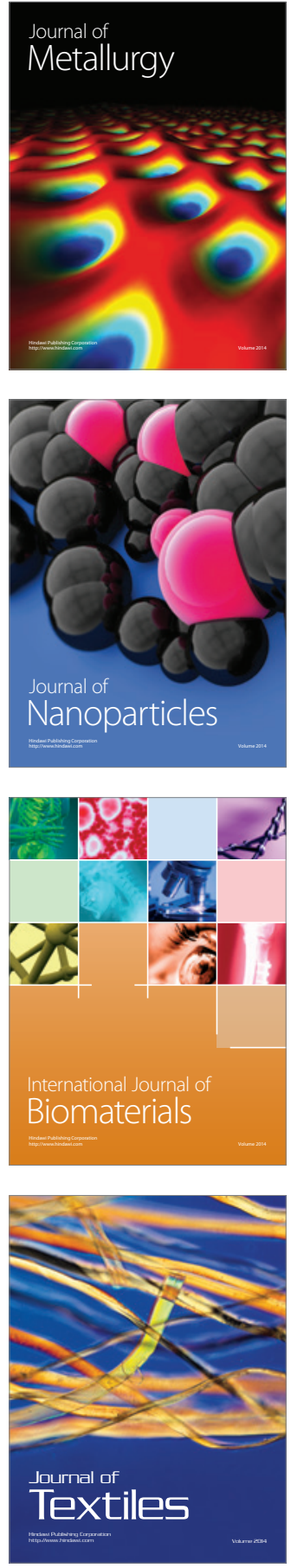